\title{
On the Ethics of Medical Care under Resource Constraints
}

\author{
Joseph Agassi*
}

This is the text of a talk given at Queen Mary Hospital, The University of Hong Kong, Fall 2003

The aim of this discussion is practical; otherwise it largely repeats some very general observations, chiefly historical and philosophical. I boast no expertise in anything specifically medical, to do with either medical care or medical administration. My concern is with the system of medicine and with the ethical and social issues that it involves. ${ }^{1}$

Applied philosophy is a still uncharted territory. Philosophers traditionally focus more on justifying accepted solutions than on seeking new solutions to urgent or interesting problems: their staple problems are those of justification. Thus, they spend less time discussing scientific problems and difficulties, and more time discussing the justification of the claims that we know. They habitually choose the simplest and most unproblematic claims for knowledge, and then try to substantiate them. As the famous writer William SomersetMaugham has observed, from reading philosophy one might get the impression that there is no pain more important than my toothache. Possibly this makes sense: philosophers discuss the justification of the claims that are most accessible, since if they cannot justify them they cannot justify anything. This is indeed the case: even to justify that I have toothache or that I see a desk before me is impossible. Philosophers often find this tormenting. And perhaps it is. Yet

\footnotetext{
* J. Agassi was born on 7 may 1927 in Jerusalem, Palestine. He received his MSc in 1951 at the Hebrew University of Jerusalem, and his PhD in Science: Logic and Scientific Method at University of London at the London School of Economics in 1956. He was research associate in the Center for the Study of the Behavioral Sciences in Stanford California in 1956-7, a lecturer in logic and scientific method at the London School of Economics (1957-1960), lecturer, then reader and head of the department of philosophy, in the University of Hong Kong (1960-1963), associate professor of philosophy at the University of Illinois at Urbana IL (1963-1965), Professor of Philosophy, Boston University, 1965-1983, Professor of Philosophy, Tel-Aviv University, Tel-Aviv, 1971-1996, Professor of Philosophy, York University, Toronto, 1982-1997, Professor emeritus, Tel-Aviv University and York University, Toronto. Agassi is primarily interested in science, metaphysics, and politics. He takes it that philosophy is nothing if not rationalist. For over fifty years he studied the rationality of science, of metaphysics and of democratic politics.

${ }^{1}$ My texts are two documents that the Hong Kong Health and Welfare Bureau published in 1999. One is the Harvard Team, Improving Hong Kong's Health Care System: Why and for Whom? The other is the comment on it by lan Holliday and Tarn Wai-keung, Hospital Authority's Submission on Improving Hong Kong's Health Care System.
}

Spontaneous Generations 1:1 (2007). ISSN 1913-0465. University of Toronto 
most people find these questions bizarre. It is much more common - and reasonable - to accept that under normal circumstances there is neither any need nor any possibility of justification. This holds particularly for knowledge claims: no knowledge is absolutely secure. This is not under dispute. Rather, most philosophers consider it essential to explain what the knowledge that is partially secure is: what makes its being partially secure. They do not know. To come nearer to the concern of this essay, most philosophers wish to justify claims that certain acts are moral and are commendable and that other acts are immoral and are condemnable. And so, again, they take the simplest cases possible. Yet moral judgments are context-dependent. The leading eighteenthcentury philosopher Immanuel Kant deemed that all justification rests on generality, and he took the case of truthfulness and lying as an example. Bertrand Russell, the famous leading twentieth-century philosopher, responded to this by narrating a story. Once, as he was taking a walk in the fields, hunters passed by him and asked him about the direction in which the fox had fled. He lied to them, he tells us, and felt no compunction about it. He did not mean to suggest for one minute that the life of a fox is more worthy than the life of a human being. Rather, he meant to poke fun at the philosophers who have no sense of what problem is pressing. Problem-oriented philosophy is practical and yet it is a relatively new outfit.

Simple considerations from sheer sense of proportion will show how prevalent problems are and how often they are difficult or even impossibly difficult to solve. It stands to reason that at times the tasks of medicine - to save lives and to prevent or cure all sorts of illness - are better performed outside the medical practice, say by preventing war. Nevertheless, it is not possible to demand of the medical profession to intervene in matters of war and peace: this is outside their field of competence. Yet they can find a place to volunteer - let me stress, volunteer - to perform tasks that are not quite within their traditional role, yet well within their field of competence. The noble examples of the hunger relief of the Swiss Red Cross in Ethiopia and of the medical services of the organization of Doctors without Borders are proof enough of that. However, there is a limit to all this. In a recent international conference, an African physician rightly observed that the amount of money equal to the cost of a single open-heart operation unit suffices to save the lives of thousands of African children by immunizing them, as immunization programs are inoperative for the mere want of funds. It is not too much to expect of everyone to see the enormous, intolerable injustice of the current immense gulf between poor and rich nations but also that the poor will not benefit greatly from the mere curtailment of services to the rich. On the contrary, they will suffer from the loss of the fruits of research, since research often aims at the immediate relief of the problems of the rich. Medically speaking, the most urgent medication is food, especially balanced diets. If all resources aimed at the most urgent problems, 
there would be nothing left for research.

Poverty is not to be ignored, however, even when planning the medical services for relatively well off places. The immigration pressure from poor countries to rich ones endangers us all. It will continue to increase until hope for improvement in poor places changes matters. Until then, every improvement of any social service in rich places, particularly educational and medical, will only aggravate matters. Therefore, again, it is not too much to expect that the enormous value of wonderful improvements will paradoxically aggravate matters by contributing to an increase in immigration pressure. Yet one must continue the good work and hope that others will do their part, and that perhaps some normal political engagement on the part of physicians as citizens may help increase freedom and security in the whole world.

The rise of modern medicine in the late nineteenth century comprised of two interlocked radical changes, one scientific-technological, the other socio-moral. They are both very conspicuous, and philosophically very problematic. The sense of proportion tells us that we should not burden physicians with detailed discussion of philosophical matters that are excessively advanced even for most professional philosophers. (For, to repeat, most philosophers are not ready to handle real problems.) Yet it seems that to some extent this is both unavoidable and beneficial. Here is an example. It is a remarkable and conspicuous fact that today relatively well informed, relatively educated western individuals, say, ones with regular high-school education, are much better informed about matters of health than the common medical practitioners were, anywhere on earth, only a century ago. Not only are people today sufficiently familiar with some very advanced medical facts, but they can take care of their own health better than experts could only a century ago. This is an example of the fact that advances real, important advances - are much more accessible than those that are kept in the hands of experts alone. This is not to speak ill of the traditional practitioners. Indeed, we should note at once that one very important function that physicians traditionally carried out was lost due to the immense progress in medicine, and that function is the medical education of the public. This is not new, and educational authorities are well aware of it. Already in the early twentieth century, as a matter of course, elementary-school nurses functioned as healthcare teachers. Nevertheless, it is about time that we add this function to the curriculum of medical education. True, the curriculum of medical education is over-full. Yet, the task is urgent. For, clearly, the function of physicians as educators was lost, not due to any ill will or disregard, but due to the difficulty of transmitting abstract knowledge to poorly informed patients, and this difficulty needs to be addressed. Medical education of practitioners, patients and the public at large requires general coordination for the betterment of all.

Until the scientific revolution, all received theories were highly intuitive. It is not that science opposes intuitions, and certainly some intuitions are right, especially those about the importance of balance (though not necessarily between Galenian humours or temperaments, and not necessarily between Yin 
and Yang or the Five Agents caused by emotions). We know that for sure. Some people say it is not so. They say Pasteur's germ theory, the discovery of etiology, particularly of bacteria, has ousted even the idea of balance. Yet, Pasteur had to acknowledge that the harm of outside agents depends to some extent on the inner constitution of their host. This is sufficiently obvious to have become the topic of a science fiction novel, The Andromeda Strain, written by a medical student by the name of Michael Crichton. Though some intuitive ideas are true, others are false, and science is free to engage in counter-intuitive speculations. To gain this freedom, science has to be free of traditional authority - not of all traditional ideas, but of all authority, including that of tradition.

Some historians of science try to explain why the rise of modern medicine came centuries later than the rise of other modern sciences. They fail to do so. Much of the progress of modern medicine is due to general advances in human knowledge, such as the development of anaesthetics in the early or middle of the nineteenth century, and the development of statistics at the same time. (Statistics revealed the fact that bloodletting is not beneficial, and anaesthesia permitted complex and sustained operations.) The chief obstacle to the rise of modern medicine, these historians of science say, is that it was full of errors, errors that it inherited from tradition. This is obviously false, since science is never free of error, and perhaps with the exception of mathematics, all science suffers some traditional error. These historians of science know this fact. This is not to deny that medicine suffers from traditional errors. However, the historic dependence of medicine on tradition was specific to it. The reason for this was moral: physicians were under pressure to do what they could. Even today many doctors recommend traditional cures that as far as we know cause no harm. Now, admittedly, there should be no objection to tradition unless it turns out to be harmful, but supporting tradition for want of anything better is a traditional error that medicine should be free of.

The revolution in medicine relates with three classmates, graduates of the Paris Hospital: Charcot, Bernard and Pasteur. The Paris hospital, says Ackerknecht, a leading historian of medicine, was the first to make a new demand: it demanded to administer no medicine unless there was a better reason for it than that it was simply traditional. This is not the only reason for the growth of modern medicine. There was also the discovery of Semmelweis that in the Vienna hospital for the poor new mothers died from fever (the so-called childbirth fever, as illnesses were traditionally named by the kind of fever they produced) because the physicians were careless about hygiene. He was ignored and worse, and only in the next generation Pasteur and Lister followed him and demanded care to avoid causing infections.

Thus, it was not error and not the want of information that caused the new developments. It was a new morality, a new attitude to facts: to approach them like any other facts of nature, with disinterest rather than with false compassion, 
with sincere desire to comprehend the causes of diseases and to examine carefully claims for the efficiency of medications.

What made the greatest difference in administering medicine was the evolution of public health, especially of preventive medicine. This development depended on improved medical knowledge, to be sure, especially etiology. It was also a development of large-scale public education. Even today public medical education continues, in the form of discussions of the ills of wrong lifestyles, including lack of exercise and bad eating-habits, that public-health officials launch regularly. The exuberance of this public health initiative has prevented any radical change in the role of physicians. They have traditionally been clinicians. Even in teaching hospitals, where professors make their rounds with entourages of students, they perform their duty the way they do it in their clinics, and this is how they have done it for centuries. There are exceptions, of course, and surgery is the most conspicuous example for that. Not in vain does the Hippocratic Oath forbid surgery.

The reason is not far to seek: however backward traditional medicine was, it was still very difficult to practice it in an intolerant, ignorant society. So physicians learned to behave in an artificial isolation. By a strictly imposed, generally admitted convention, the clinical encounter happens in a social void and in a minimal moral context: do no harm. That is all. This is a wonderful preventive measure against the participation of physicians in official crimes, but it also prevents their active participation in political improvements as physicians. These days it is not good enough, as today physicians are often forced to participate in torture on the ground that this reduces the chance that the torturers kill their victims by mistake. There is still no solution to the problem of under what conditions physicians should cooperate with torturers. There is a more general problem: physicians are often forced to play God. Perhaps some perverse people enjoy the power that this seems to offer them, but we should ignore them now. The fact remains that playing God happens because of shortage and is justified in this way. And God has no shortage as far as we know. Moreover, we try hard to prevent this pressure on physicians; we try hard to prevent such situations and to make rules, such as those for triage, when it is impossible to avoid them. This is sufficiently well known to be a standard feature of medical television programs, particularly E. R. (of the same Michael Crichton, incidentally). However, this is not always possible and it is never satisfactory.

This was publicized in the first play that exhibited this problem, a century ago, aptly called The Doctor's Dilemma, by Bernard Shaw. The doctor in the play has one dose of a new cure, and he has as patients two acquaintances to practice it on, one an honest dedicated physician, the other a great artist but a rogue. No rules can cover such cases. In general, we use the double-blind method of testing medications, and we forbid private use of untested medications. This is similar to the use of lots to decide which member of a platoon will go on a dangerous scouting mission. Yet the question remains: how do societies generate rules regarding life-and-death decisions under severe 
constraints?

When medication is relatively easily available, the problem is less pressing and then people tend to ignore it if they can. Some medications of necessity are too expensive to be staple items in public health services, and then those for whom it is a matter of life and death clamour for it. Shaw noted all this a century ago. In the preface to the aforementioned play he said that the dying may be ready to pay as much as they can in efforts to prolong their lives, but society must put a price tag on such efforts. A misguided sense of morality has led to a total oversight of this point. Worse still, some socialist thinkers said, ever since the establishment of the Soviet Union, that we can and should forego all luxury in order to save for things of higher priorities, including saving lives and catering for a better future for our children.

Of course, this is not true. The citizens of communist states gave up luxury with no assurance of any benefit. Even simple medications for old people were often denied, and major spending went to armament and monstrous waste. Nevertheless, we may put these facts aside, and ask ourselves the question in a philosophical mood: should we try to have a society with no luxury and in exchange try to save lives? This question comprises a genuine challenge. Unless we can answer it, our attitude seems morally defective.

There are two responses to that challenge. The first is that abolishing luxury for the sake of prolongation of life is not optional". Everyone can volunteer to be altruistic and give up all luxury for a good cause. Some people are known to have done this, and not in vain they are deemed saints. Most of us cannot do it and governments that try to force us to do it are of necessity as bad as the regimes of Eastern Europe whose citizenries deemed them intolerable and so risked their lives in an effort to cause their downfall. Fortunately, they succeeded.

The second response goes deeper. The choice in question is one of lifestyle. Do we all want to live as long as possible with no luxury or do we prefer to live fewer years but in luxury? An item of luxury is by definition one that we can do without. But can we do without any item of luxury? Is luxury as such something we can at all do without? Even the communist propagandists knew that the answer is in the negative: we can do without luxury for a while, and this is what they demanded, but the while became a lifestyle, the notorious grey lifestyle under communism.

All this is scarcely new. Canada sees that mental health is a part of its responsibility, and that a reasonably satisfying lifestyle is essential for a healthy mind. This in effect closes the discussion about the question, should we do without luxury? But the question remains: how much luxury is reasonably permissible, especially in a world like ours, troubled by hunger, war and pestilence. A satisfactory general answer to this question is in principle not possible. And the question then spills over to more practical questions that relate to it, such as how much tax should a government levy from its wealthy 
population so as to be able to improve social services, including medical services. I submit that this kind of question eludes satisfactory general answers and even general criteria for satisfactory general answers.

Nevertheless, certain ideas are practicable, and implementing them will definitely open the road to better ideas. First is the idea of improving efficiency. It is not as simple and straightforward as it looks, since it has many aspects. For example, improving diagnostic techniques is of tremendous import on many levels, and many medical reforms are due to such improvements. This is particularly true as long as most practicing physicians still have the narrow view that their function is limited to the clinical encounter, since consulting laboratories are then taken to be mere technical extensions of the clinic on the fictitious suggestion that lab examinations and reports are morally and socially unproblematic. (Some lab examinations are notoriously problematic. When we think of them, we do not take them as mere extensions of the clinical encounter just because they are problematic.) The same goes for the use of computers, not only because it improves physicians' control over their calendars, but also, and more so, because they get forms to fill, such as forms of anamnesis. This improves anamnesis significantly, especially in a world of travelers, and especially with the dissemination of medical smart cards - perhaps as obligatory for travelers or even for all citizens. This also harbours great dangers, as the forms may easily lead to a frozen mode of conduct and to other bureaucratic ills that are less obviously significant for saving life but that may be more pertinent to it nonetheless. This matter is too vast to discuss here.

To take matters further, we may take a bold step, break the fiction that the clinical encounter takes place in a social void and try to link medical efficiency to the integration of medical practice with the lifestyle of the country that should abide by it. This opens new vistas of many kinds. Hopefully in due course this will turn out to be more challenging and more rewarding. The integration should spill over at once to avenues that thus far have suffered neglect due to lack of any coordination between social bodies. In particular, more people would be able to serve in medical functions, professionally or voluntarily or in between, and their functions could be upgraded by rules that are now being implemented or tried out in different places. Information will easily raise efficiency. It is clear that the Chinese communists allowed traditional Chinese medicine not because of conviction - after all, communist hostility to tradition is proverbial - but because of shortage of work force. By contrast, western countries do not even allow military medics to practice after their discharge. This is a great waste. The waste has rationale of course, rooted in the wish to overcome certain difficulties, but better means of overcoming these difficulties are possible, and it is hard to avoid suspicion that the medical organizations are at times more concerned with their members' income than with public health. I cannot offer a worse example for that than the manual of psychiatry published by the American Psychiatric Association and known as DSM. It offers as its guidelines the lowest common denominator of all psychiatric and psychotherapeutic schools while using a 
defunct terminology that rests on an inept philosophy of science. What it does is enable its members to get away with gargantuan waste.

Admittedly, concern with the welfare of physicians is a concern of us all: it is in the interest of everybody that doctors should fare well. This is not to say that the leaders of the medical profession always act in their own interest. In some famous cases, medical leaders have worked against the public interest in order to defend the interest of the profession, but erred about that interest. The paradigm case here is the hostility of the American Medical Association to the national program for providing for medical care for the elderly: these people feared that the program would reduce the income of physicians, although it did the very opposite. The same goes for the traditional vigilant support for the monopoly of the medical profession over the health care of the population at large. Quite generally, the concern with the interest of physicians is never divorced from the concern for the health of the public at large; the impression that there is a conflict here is due to a very widespread illusion. Thus, it may appear as if the popularity of gourmet cooking, for example, is detrimental to proprietors and employees of gourmet restaurants. Not so. The wide spread of poor quality fast food chains does that, not the evolution of tastes. Vendors of computer programs discovered the same. Programs are stolen left and right, yet learning to use good computer software only improves the lot of software engineers. And, likewise, the more public medical knowledge, the more first-aid volunteers, the more people at every level of medical proficiency, the better off the whole profession will be. Imagine an ideal society, one in which everyone is in possession of the best medical knowledge and the best means for its implementation. In such a society, there will be no professional physician, you may think. But you would be in error: many services prove this point. Make the picture a bit less Utopian. Assume everyone to be fairly expert but not quite. Surely in that society experts proper may be less often in demand, but, I dare say, they will be the cream of the cream.

Let me conclude, then, with a point about ethics. Since philosophers wish to justify ethics, they have two traditional avenues: justify conduct by the good intentions behind it or justify conduct by its good results. Everyone knows that both avenues are blind alleys, as both acts based on good intentions and acts that somehow led to good results may be unjustifiable. Moreover, the interesting cases are those over which we still have no opinion, at least not a generally agreed one, so that there is here nothing to justify. The literature on the topic is full of such examples, and philosophers try to pass judgment on them based on received principles, mainly that of respect for life and that of respect for the judgment of all individuals regarding their own affairs (and thus the rejection of paternalism). This does not suffice, not even after we add to these two principles the valuable demand for the responsibility of actors who do their best to avoid doing harm. We can never fully remove harm. The same holds for 
error. To err is human and error leads to harm. But this is no license to act irresponsibly. The view of science as error-free has repeatedly led to the unjust condemnation of physicians who acted in good faith and by the book but with sad results. This is why we have inquests: inquests are due to some unfortunate results and efforts to find out if these results are due to irresponsibility. It is an amazing fact that responsibility is so much a part of the modern world yet scholars have been so slow to discuss it. The first social scientist to discuss it was Max Weber, just over a century ago, and the first philosopher to discuss it was Karl Popper, over half a century ago.

This is a point of great practical importance. Undoubtedly, monitors greatly increase the efficiency of every system yet the refusal to install monitors is widespread, usually on the ground that the dependability of the individuals monitored is thereby put to question. This is a common error. The monitor is the best friend of those who may find themselves under suspicion, and physicians are the paradigm of this kind of people. The same goes for second opinions. On the whole, the idea that we should not place people under a conflict of loyalty is not due to suspicion but on the contrary due to the desire to prevent suspicion. And still, many surgeons diagnose and operate on the basis of their own diagnosis alone. Insurance companies know this, and they always are ready to pay for second opinions. But patients seldom know about this and so they do not avail themselves of this service. Their diagnosticians are duty-bound to tell them, but they do not do so as often as they should. This is where it is possible and even easy to enhance efficiency greatly and cheaply: the education of physicians to see that the care of their patients is in their own best interest. Most philosophers do not see this. Following tradition, they try to reduce ethics to egoism or to altruism. They thus do not see that proper action is the mix of egoism and altruism. This leads to the view that what makes this mix moral is the sense of responsibility, especially the responsibility that leads one to criticize one's views and one's actions both egoistically and altruistically. Critical thinking serves the effort to avoid error as much as humanly possible but without blame for the inevitable sad results that human conduct is bound to have from time to time. Not stressing this raises tension, and a physician who lives in tension is less able and less happy than one who is at peace. This is not news, but it is also not sufficiently a part of our common understanding. One way to make life easier is to make it so. To that end, it is useful to explain repeatedly that propagating the idea that physicians are infallible is unwise.

JOSEPH AGASSI

37 Levi Eshkol Street

Herzliya 46745 Israel

+ 972.9.950.4072

agass@post.tau.ac.il

http://www.tau.ac.il/ agass/ 